\title{
A IMPORTÂNCIA DO ATENDIMENTO EDUCACIONAL ESPECIALIZADO PARA OS AUTISTAS
}

\author{
Eunice Januária Moreira \\ Renan Augusto de Souza
}

Resumo: Este trabalho trata da relevância do atendimento educacional especializado para os autistas. Tal abordagem se justifica pela importância e necessidade do autista ter um acompanhamento diferenciado dos demais, pelo fato de seu aprendizado ocorrer de forma diferenciada, e sabemos que o lúdico é um dos maiores fios condutores para a aprendizagem acontecer. O propósito deste trabalho é analisar o quanto a sala de Recursos conhecida nas escolas como sala de Atendimento Educacional Especializado (AEE), poderá ajudar essas crianças a se desenvolverem tanto seu lado acadêmico como social, visto que é de suma importância para a sua maior independência. Não podendo deixar de enfatizar que nesse atendimento educacional especializado ocorre enfatizando sempre as potencialidades das crianças e trabalhando as de mais dificuldades. Seu ponto chave sempre deverá ser o foco de interesse do indivíduo. Compreendendo que se a criança está motivada, o aprendizado é satisfatório. A pesquisa em pauta evidenciou a importância de todos os autistas terem esse atendimento educacional especializado, mesmo tendo uma mediadora especial junto a ele na sala de aula. O atendimento correto ajudará em seu melhor desenvolvimento tanto na área escolar quanto social.

Palavras Chaves: Autismo. Atendimento Educacional Especializado. Aprendizagem. Lúdica.

\section{INTRODUÇÃO}

Partindo do princípio da análise da inclusão escolar, vemos cada dia mais a inclusão de crianças autistas ao âmbito escolar. Sabendo que a mesma vem acontecendo cada dia mais, mas que ainda necessita ter inúmeros avanços para que os benefícios sejam melhores para o indivíduo, podemos afirmar que o Atendimento Educacional Especializado mais conhecido nas escolas como sala de AEE foi um excelente avanço para as crianças.

Ao fazer uma abordagem acerca da importância do atendimento educacional especializado se faz necessário evidenciar as características básicas do autismo, para que possamos conhecer algumas particularidades, dificuldade e habilidades do mesmo. E compreender porquê o atendimento educacional especializado para ele é de tanta relevância.

Para tanto o primeiro aspecto a ser abordado refere-se ao conhecimento das características básicas do autismo, quais suas características para que possamos identificar quando algo pode estar errado com seu filho em casa, ou um aluno na escola. 
Dentro dessa perspectiva no segundo capítulo será abordado o quanto o atendimento educacional especializado tem o papel de ajudar o individuo fazendo com que o mesmo tenha um desenvolvimento satisfatório, dentro de suas necessidades e dificuldades.

Finalmente a pesquisa encerra esta discussão evidenciando o atendimento educacional especializado como um aliado no desenvolvimento dos autistas, fazendo com que o mesmo consiga vencer suas dificuldades. Visto que somos seres únicos, tendo suas particularidades individuais.

\section{CARACTERÍSTICAS DO AUTISMO}

O TEA, conhecido como Transtorno do Espectro Autista, bem como outras inúmeras síndromes e deficiências ainda na atualidade são cercados por atitudes de enorme preconceito que muita das vezes ocorre através de pessoas que ainda não adquiriu conhecimento acerca do assunto. $\mathrm{Na}$ maioria das vezes o olhar para certa criança que esteja fazendo uma birra ou tendo atitudes diferentes das típicas ditas pela sociedade, faz com que o julgamento aconteça, sem ao menos compreender que aquela criança é autista e pode estar passando por uma crise por inúmeros motivos (RODRIGUES, 2010).

A aparência física dos autistas, a princípio, não expõe a dimensão exata da gravidade do problema, cujos sintomas iniciais surgem antes dos dois anos e seis meses de nascimento do bebê. Em geral, são crianças de traços singelos e de feições bonitas (RODRIGUES, SPENCER, 2010, p. 20).

A citação acima nos relata que os autistas não possuem aparências físicas diferenciadas como no caso da síndrome de Down, e por serem consideradas crianças fisicamente normais, aos olhos da sociedade, se torna motivo de surpresa e questionamento quando se vê um autista fazendo algo diferente das demais crianças.

Os sinais do autismo podem ser observados muito cedo, antes mesmo dos três anos de idade, visto que algumas ações e reações normais de acontecer no decorrer do desenvolvimento em uma criança típica, na autista se fazem ausentes. Por sua vez, os pais nos relatam que, nos primeiros anos de vida do bebê autista, percebem um atraso de expressão facial, direcionamento de atividades, e constatam certa passividade do bebê (bebê hipotônico) (RODRIGUES, 2010).

Rodrigues e Spencer (2010) nos apresenta em seu livro A criança Autista. Um estudo psicopedagógico. Diversos relatos de mães de autista que comprovam realmente os estudos de 
diversos autores que estudam sobre o assunto. Na citação acima, o relato é de um pai que relatou ver sinais anormais em seu filho que foi diagnosticado com autismo muito cedo, ainda na primeira infância. O atraso ou a falta de sorrisos, compartilhamento de olhares, sua expressão facial na maioria das vezes é padrão e não sofre variações de acordo com o estímulo recebido do meio que o acerca. Sua passividade faz as maiorias das mães pensarem que ele não está a ouvindo-a ou está se fazendo de bobo, pois um exemplo bem comum é o chamado pelo nome da criança. Na maioria dos autistas não há nenhuma resposta, nem se quer olhares ao rumo do chamado.

O Transtorno do Espectro Autista refere-se a uma série de outras condições caracterizadas por desafios com habilidades sociais, como por exemplo, o contato precário com pessoas que estão a sua volta, bem como a falta de contato olho no olho. Comportamentos repetitivos, esses se caracterizam pela famosa estereotipia que são os movimentos repetidos em excesso. E temos por fim a fala e a comunicação não-verbal, hoje no nosso cenário social, nos deparamos com autistas verbais, que pronunciam falas inteiras e possuem conversas fluentes na comunicação, como também nos deparamos com autistas não-verbais, os quais não fazem uso da fala para se comunicarem. (FACION, 2007).

O autismo é uma síndrome, portanto um conjunto de sintomas, presente desde o nascimento e que se manifesta invariavelmente antes dos três anos de idade. Ele é caracterizado por respostas anormais e estímulos auditivos e/ou visuais e por problemas graves na compreensão da linguagem oral. A fala custa a aparecer e, quando isso acontece, podemos observar a ecolalia (repetição das palavras), o uso inadequado de pronomes, estrutura gramatical imatura e grande inabilidade para usar termos abstratos (FACION, 2007, p. 27).

A citação acima nos demonstra o quão cedo pode ser percebido os sintomas do autismo, e que o atraso ou a não verbalidade da criança é um dos pontos principais do autismo, visto que traz muitas consequências para o mesmo. Na maioria das vezes a criança não consegue se comunicar rapidamente e isso acarreta um desequilibro do mesmo, fazendo com que ele fique muito nervoso, e nos casos mais severos até muito agressivo. Esse é um fator muito observado, pois o falar é uma fase do desenvolvimento infantil esperado com muito entusiasmo pelos pais de uma criança. (FACION, 2007).

O transtorno autista apresenta-se como uma desordem no desenvolvimento que se manifesta desde o nascimento, de maneira grave e por toda a vida. Acomete cerca de 20 entre cada 10 mil nascidos e é 
quatro vezes mais comum entre meninos do que entre meninas. Quando a menina é acometida, normalmente, os sintomas são mais graves. Esse transtorno é encontrado em todo o mundo e em famílias de qualquer configuração racial, étnica ou social. (FACION, 2007, p. 26).

Segundo Facion (2007) esse transtorno é encontrado em todo o mundo e em diversas famílias, contudo, ainda não se chegou à conclusão de sua real causa, podendo o referido transtorno acarretar de leve a severos sintomas. O transtorno autista é mais comum nos meninos, por essa razão, o autismo é simbolizado com a cor azul. Já nas meninas, os casos são raríssimos e quando ocorrem, os sintomas são muitos e mais fortes. As meninas na maioria das vezes apresentam mais sintomas, o atraso consequentemente é maior entre outras causas.

Os sintomas mais comuns em pessoas com os transtornos são: usar pessoas como ferramenta, resiste à mudança de rotina, não se misturam com outras crianças, não mantém contato visual, agem como se fossem surdos, não demonstram medo de perigos, resiste ao contato físico, às vezes é agressivo e destrutivo, acentuada hiperatividade física, entre outros. Toda essa variedade de sintomas entre uma criança e outra contribui possivelmente para que se torne mais difícil traçar um perfil único e exclusivo de um transtorno como o autismo (FACION, 2007, p. 31).

Os sintomas são muitos, e pode variar de criança para criança. Sendo assim não podemos ver o autista como todos iguais, compreendendo que somos seres humanos único, individuais. Pode acontecer de terem sintomas semelhantes, porém gostos e interesses totalmente diferentes. Por essa razão o elo família/escola é fundamental. O trabalho sempre tem que ser interdisciplinar para que possamos compreender melhor o indivíduo em seu todo (SUPLINO, 2009).

Sendo assim a busca pelo diagnóstico precoce é sempre a melhor alternativa, pois desde cedo você terá condições de ajudar no melhor desenvolvimento da criança. O diagnóstico precoce é o primeiro grande instrumento da educação (CUNHA, 2016, p. 23). Quanto mais tarde ser dado o diagnóstico menor será o tempo de intervenção corretamente, ajudando em áreas de suma importância para o seu melhor desenvolvimento. Pois a partir de seu diagnostico e acompanhamento com profissionais da área será possível saber quais as áreas mais afetadas para serem trabalhadas e estimuladas da forma correta.

\section{O ATENDIMENTO EDUCACIONAL ESPECIALIZADO}

Para começarmos devemos compreender o que é o Atendimento Educacional 
Especializado conhecido também nas maiorias das escolas como sala de AEE. Essa sala é destinada a atender crianças com deficiências, transtornos e dificuldades.

O Atendimento Educacional Especializado é de suma importância, pois favorece a peculiaridade de cada aluno principalmente dos alunos com necessidades educacionais especiais. É uma forma de propiciar oportunidades para inclusão sendo um espaço de transição para aquisição de hábitos e atitudes, facilitando a convivência social numa classe especial ou regular de ensino.

Sendo assim podemos compreender que essa sala de recurso é como um apoio pedagógico durante o processo de formação acadêmica, ou seja, durante todo o processo de conhecimento e desenvolvimento de um indivíduo com alguma necessidade educacional especializado. O professor do AEE, dependendo da necessidade de seu aluno, irá organizar atividades e recursos pedagógicos e de acessibilidade a fim de facilitar o processo de construção de aprendizagem do sujeito (SECRETARIA DE ESTADO DE EDUCAÇAO DE MINAS GERAIS, 2013).

O Atendimento Educacional Especializado (AEE) tem como função complementar ou suplementar a formação do aluno por meio da disponibilização de serviços, recursos de acessibilidade e estratégias que eliminem barreiras para sua plena participação na sociedade e desenvolvimento de sua aprendizagem (SECRETARIA DE ESTADO DE EDUCAÇÃO DE MINAS GERAIS, 2013, p. 13).

Pode-se dizer que esse atendimento é um serviço exclusivamente da Educação Especial. Deve-se deixar claro que sua função não é a realização de aulas, mas atendimentos planejados de acordo com cada necessidade do indivíduo que lá se encontra para receber o atendimento, auxiliando na eliminação de barreiras para sua plena participação na sociedade. O professor deverá, de forma criativa e inovadora, buscar atividades e recursos que estimulem o aprendizado do aluno naquelas áreas em que ele encontra maiores dificuldades. Não podemos deixar de enfatizar que no caso do autismo esse recurso de criatividade é indispensável, sabendo que eles possuem um centro de interesse muito restrito e coisas criativas e diferentes chamam a sua atenção. Ainda mais quando levamos em conta o quanto o autista na maioria das vezes é visual, mantendo enorme contato com o que chama atenção.

A escola deverá ter um plano de AEE para a identificação das necessidades educacionais especializadas dos alunos, assim como para a definição dos recursos e atividades que serão 
desenvolvidas, tendo em vista as especificidades dos alunos.

Portanto, quando se fala que cada aluno ira receber acompanhamento diferenciado na sala de AEE, devemos conhecer o Plano de Desenvolvimento Individual (PDI), pois este é o responsável por traçar metas para cada indivíduo, e através dessas metas traçadas começam os trabalhos para que eles sejam vencidos. O PDI é um norte para seguirmos quando identificaremos as necessidades educacionais dos alunos a cada momento de sua vida, apoiando assim nas orientações e na elaboração das atividades que serão aplicadas na sala.

O professor terá que pensar, caso a caso, qual a melhor forma de trabalhar com o aluno, quais os recursos a serem utilizados para que a construção de sua aprendizagem seja levada a termo (MANTOAN; PRIETO, 2006).

O Plano de Desenvolvimento Individual (PDI) é o instrumento obrigatório para o acompanhamento do desenvolvimento e aprendizagem do aluno com deficiência, transtornos globais do desenvolvimento e altas habilidades/superdotação. Deve ser elaborado, desde o início da vida escolar do aluno, por todos os profissionais (diretor, especialista e professores envolvidos no processo de escolarização), em parceria com a família e atualizado conforme temporalidade prevista no Projeto Político Pedagógico da escola (SECRETARIA DE ESTADO DE EDUCAÇÃO DE MINAS GERAIS, 2013, p. 8).

Assim sendo, nota-se que o PDI é um instrumento que acompanha o indivíduo ao longo de sua aprendizagem e ele é elaborado com uma equipe multidisciplinar aonde que diferentes olhares e conhecimentos, demarcam o que primeiramente deve ser trabalhado e assim sucessivamente de acordo com o nível de desenvolvimento da criança.

Quando se fala de acordo com o nível de desenvolvimento da criança, podemos tirar como exemplo as crianças do Espectro Autista. O laudo vem igual para todos os autistas, porém o que mais precisa ser trabalhado em cada um deles são suas maiores dificuldades, que serão identificadas por profissionais que possuem o domínio na área, como psicólogos, psicopedagogos e o professor que trabalha na sala de AEE. Pois, inúmeros estudos comprovam que cada criança autista vem com uma maior limitação em uma área, algumas na linguagem, outras na cognição e assim por diante. Por essa razão, o Plano de Desenvolvimento Individual é um termo obrigatório quando tratamos de educação inclusiva.

A finalidade do Atendimento Educacional Especializado é de ajudar a criança na 
aprendizagem que não ocorreu dentro da sala de aula, pois a forma tradicional de aprendizagem na maioria das crianças com algum transtorno não acontece. Eles necessitam de atividades estruturadas, de forma simples e do interesse dele. Em razão disso, hoje os maiores sucessos de desenvolvimento de autistas são com atividades focadas em seu centro de interesse, que o motiva a realizar a atividade, pois estas e os jogos são montados exclusivamente para ele com personagem e desenhos que ele mais gosta no momento, por efeito se terá uma criança supermotivada a aprender.

As atividades nesta sala têm uma dinâmica de trabalho condizente com as potencialidades e necessidades dos alunos e dos recursos a serem adaptados, utilizando materiais diversificados tais como jogos pedagógicos, pranchas de comunicação, computador, massinha, cola colorida, colagem, tinta guache, recortes, gibis, livros de histórias, argila, bola, corda, lápis mais grosso, papel A3, revistas, jornais, DVD, cd's, entre outros. (SECRETARIA DE ESTADO DE EDUCAÇAO DE MINAS GERAIS, 2013)

Quando o aprendente gosta do que faz e está motivado, o foco da mente torna-se mais fácil, mesmo diante das dificuldades da tarefa. Quando conseguimos atrair a sua atenção, ele cria oportunidades e ganhos no seu aprendizado. A atenção é extremamente relevante na aprendizagem escolar. Os pensamentos não estão separados das experiências exteriores, mas se conectam a elas e atuam em nosso desenvolvimento cognitivo à medida que experienciamos situações cotidianas. Essas situações, então, podem servir para criar o foco de atenção, principalmente àquelas que tragam sentido ao trabalho escolar (CUNHA, 2016, p. 64).

Cunha (2016) ressalta que a motivação é um dos aspectos de suma importância para que o indivíduo se interesse pela atividade, e interessando automaticamente seu aprendizado será satisfatório. Pois sua mente estará focada. Assim a concentração ajudará as informações chegar, mas rápido a ele e os pensamentos aleatórios não acontecerão.

Para a inclusão na Escola Regular é indispensável contar com salas de apoio, como por exemplo, a sala de Atendimento Educacional Especializado, assim como, professores especializados para que se obtenha êxito na inclusão desses alunos. "A formação de profissionais da educação é tema de destacado valor quando a perspectiva do sistema de ensino é garantir a matrícula de todos os alunos no ensino regular, particularmente na classe comum" (MANTOAN; PRIETO, 2006, p. 56). 
O professor regente de uma sala de apoio teve ter um conhecimento bem elaborado de todos os transtornos, síndromes e déficits que temos hoje em dia, pois a qualquer momento uma criança que necessita do atendimento educacional especializado pode ser matriculada no âmbito escolar, visto que é garantido por lei seu direito de frequentar as escolas regulares (MINISTÉRIO DA EDUCAÇÃO, 2007).

A nova proposta de Educação Inclusiva recomenda que todos os indivíduos portadores de necessidades educativas especiais sejam matriculados em turma regular, o que se baseia no princípio de educação para todos. Frente a esse novo paradigma educativo, a escola deve ser definida como uma instituição social que tem por obrigação atender todas as crianças, sem exceção (MINISTÉRIO DA EDUCAÇÃ̃O, 1999, p. 31).

Frente ao novo paradigma educativo que é o da inclusão, a formação continuada na educação inclusiva se faz fundamental. Pois não é apenas a realização da matrícula que garantirá a inclusão e sim os preparos dos profissionais da educação que fará valer a inclusão integral do indivíduo.

Pois é a busca do conhecimento que é o alicerce do sucesso. Deve-se sempre estar buscando métodos de ensinos mais eficazes, mais produtivo a criança que ali se encontra para um apoio pedagógico diferenciado do da sala de aula.

Uma formação adequada para se atender o aluno com autismo seria ideal para o seu sucesso escolar. No entanto, percebe-se uma grande carência na formação continuada dos profissionais na rede de ensino (MINISTÉRIO DA EDUCAÇÃO, 2007).

Precisamos, então, investir com seriedade na formação inicial e continuada dos profissionais da educação e, de forma mais específica, na formação do magistério para todos os níveis e modalidades educacionais. Esta formação, em todas as instâncias, precisa concordar com a política educacional brasileira vigente que prevê a inclusão/integração dos alunos com necessidades especiais no ensino regular e, também com a oferta de serviços de Educação Especial para atender às necessidades educativas especiais (MINISTÉRIO DA EDUCAÇÃO, 1999, p. 69).

É na Educação Inclusiva que se atende esses alunos com qualidade, mas tem que dar condições e formação aos profissionais também, para que os objetivos e o desenvolvimento aconteçam corretamente. Ao longo de todo o processo, a maioria dos profissionais envolvidos na educação não sabe ou desdenham a importância e a diferença da educação especial e a educação inclusiva. 
Não se pode deixar de salientar o quanto é fundamental o Atendimento Educacional Especializado para os autistas, pois é a partir de técnicas, estratégias e experiências diferenciadas que sua aprendizagem acontecerá. E não podemos pensar que são apenas aprendizagens acadêmicas, pois nesse atendimento estará sendo trabalhada a parte social, para uma vida menos dependente. (FACION, 2007).

\section{CONSIDERAÇÕES FINAIS}

Neste momento, é oportuno retomar a hipótese inicial a respeito da importância de conhecermos os sinais do autismo, para que possamos identificar com mais facilidade, segurança e reconhecer a suma importância dos autistas receberem o Atendimento Educacional Especializado.

Compreender os sintomas do autismo dará um suporte maior para uma possível intervenção precoce na vida do mesmo, sabendo que quanto mais cedo for diagnosticado e iniciada as intervenções necessárias o desenvolvimento do indivíduo será mais satisfatória. Outro ponto importante é que o conhecimento sobre o assunto faz com que o preconceito, os olhares estranhos possa ganhar menos força a cada dia.

Pode-se afirmar também, que segundo estudos realizados acerca do tema, o Atendimento Educacional Especializado será um suporte eficaz para que o autista se desenvolva tanto na área acadêmica, como na social. Pois nesse atendimento serão trabalhadas suas dificuldades de forma diferenciada da sala de aula, de forma mais lúdica e prática. Que no caso dos autistas o prático é indispensável. Focar em seu centro de interesse do momento ajudará tanto o professor a trabalhar com a criança, quanto o aprendizado do indivíduo. Sabendo-se que o aprendizado do mesmo é a função do Atendimento Educacional Especializado. Ele é um amparo para que a criança possa estar incluída verdadeiramente na sala de aula.

Este estudo exige um maior aprofundamento, pois o exposto configura-se apenas como esboço acerca do tema e um apontamento para reflexões mais profundas e coleta de dados específicos.

\section{REFERÊNCIAS}

BRASIL. Ministério da Educação (1999). Secretaria de Educação a Distância. Educação Especial: tendências atuais. Brasília. 1999. 
BRASIL. Ministério da Educação (2007). Secretaria de Educação Especial. Educação Inclusiva. Atendimento Educacional Especializado para a Deficiência Mental. Brasília. 2007.

CUNHA, Eugênio. Autismo e inclusão: psicopedagogia práticas educativas na escola e na família. 4 ed. Rio de Janeiro: Wak Editora, 2012.

CUNHA, Eugênio. Autismo na escola: um jeito diferente de aprender, um jeito diferente de ensinar. 4 ed. Rio de Janeiro: Wak Editora, 2016.

FACION, José Raimundo. Transtornos do desenvolvimento e do comportamento. 3 ed., Curitiba: Editora IBPEX, 2007.

MANTOAN, M. T. E; PRIETO, R. G. Inclusão Escolar. São Paulo: Editora Summus, 2006.

RODRIGUES, Janine Marta Coelho. SPENCER, Eric. A criança autista. Um estudo psicopedagógico. Rio de Janeiro: Wak Editora, 2010.

SECRETARIA DE ESTADO DE EDUCAÇÃO DE MINAS GERAIS. Guia de Orientação da Educação Especial na rede estadual de ensino de Minas Gerais. 2013.

SUPLINO, Maryse. Ensinando a pessoas com autismo e deficiência intelectual. 1 ed., Rio de Janeiro: Editora Diferenças, 2011. 